\title{
WITTGENSTEIN E A HERMENÊUTICA ${ }^{1}$
}

\author{
Rui Sampaio da Silva \\ Universidade dos Açores
}

A hermenêutica é habitualmente definida como a teoria ou filosofia da interpretação e, por vezes, como a teoria da compreensão. Todavia, o termo "hermenêutica" é também usado para caracterizar uma corrente filosófica protagonizada pelas figuras de Heidegger, Gadamer e Ricoeur, a qual atribui um papel central ao problema da compreensão e da interpretação. Deste modo, os programas de hermenêutica (enquanto disciplina filosófica) são normalmente concebidos a partir da perspectiva da filosofia hermenêutica, remetendo para a penumbra autores contemporâneos conotados com outras correntes filosóficas, mas igualmente interessados numa reflexão filosófica søbre a compreensão e a interpretação, como são os casos de Wittgenstein, Davidson e Rorty.

No presente-artigo,-tenta-se-contrariar-esta-tendência, explicitando $\theta$ significado da obra tardia de Wittgenstein para a hermenêutica. ${ }^{2} \mathrm{~A}$ análise não se restringirá à reflexão wittgensteiniana sobre a interpretação e a compreensão, visto que se procurará também estabelecer um confronto en re Wittgenstein e o pensamento hermenêutico de Heidegger e de Gadamer.

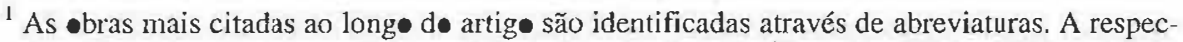
tiva lista encontra-se na última página. As citaç̃̃es de Über Gewißheit, Philosophische Untersuchungen e Zettel, apesar de feitas a partir do original, seguem, em geral, as traduções já dissponíveis em português:

- Da Certeza (trad. de Maria Elisa Costa e revisão de Antóni• Fidalgo), Lisboa, Edições 70, 1990.

- Tratado Ĺgico-Filosófic * Investigaçōes Filosóficas (trad. de M. S. Lourenço), Lisboa, Fundação Calouste Gulbenkian, 1995.

- Fichas (trad. de Ana Berhan da Costa e revisão de Artur Morão), Lisboa, Edições 70, 1989.

Sempre que, numa citação destas obras, surgirem parênteses rectos, tal significa que se optou por modificar ligeiramente a tradução da passagem citada.

2 Apesar de se privilegiar a obra tardia de Wittgenstein, serão feitas referências ocasionais a textos do períede de transição, sempre que tal se revelar pertinente.
} 
O significado hermenêutico do pensamento de Wittgenstein será esclarecido de acordo com a seguinte ordem: em primeiro lugar, mostrar-se-á em que medida se pode falar da existência de uma fenomenologia da quotidianidade na obra de Wittgenstein; em segundo lugar, será explicitada a relevância hermenêutica da concepção wittgensteiniana da certeza; em terceiro lugar, explorar-se-á a concepção do significado como uso; em quarto lugar, será abordado o tema da universalidade e da autonomia da linguagem; em quinto lugar, esclarecer-se-á a concepção wittgensteiniana da compreensão como uma capacidade prática; a sexta e última parte do artigo tratará das eventuais implicações relativistas do pensamento de Wittgenstein. Em cada uma destas etapas, as ideias de Wittgenstein serão relacionadas com aspectos da reflexão hermenêutica de Heidegger e de Gadamer.

\section{A fenomenologia da quotidianidade}

Com Heidegger e Wittgenstein, a herança cartesiana e, com ela, a teoria moderna do conhecimento são abaladas nos seus alicerces básicos, a saber: a ideia de um sujeito autónomo, enquanto domínio interior contraposto a um domínio de objectos exteriores; a concepção do conhecimento como representação correcta da realidade; e a crença na existência de representações ou proposições privilegiadas que constituíssem um fundamento sólido do conhecimento. Com efeito, ambos criticam a distinção entre uma esfera interior (o sujeito) e um mundo exterior, ao mesmo tempo que subvertem a concepção clássica do conhecimento, mediante uma investigação da dimensão social e pragmática do conhecimento. Problemas tradicionais, como o da prova da existência de um mundo exterior, são simplesmente dissolvidos. $\mathrm{Na}$ origem de tal processo ou revolução está aquilo a que se poderia chamar uma fenomenologia da quotidianidade, ${ }^{3}$ isto é, uma concepção da filosofia orientada para uma descrição da experiência e das práticas quotidianas.

Assim, e em consonância com a tradição fenomenológica, Wittgenstein considera a filosofia como uma tarefa puramente descritiva e rejeita o recurso teorias, hipóteses ou explicações. ${ }^{4}$ Nas Investigações Filosóficas, afirma inclusivamente que "[t]oda a explicação tem que acabar e ser substi-

${ }^{3}$ Ver, a este respeito, Charles Guignon, "Philosophy after Wittgenstein and Heidegger", Philosophy and Phenomenological Research 50 (1990) e Stephen Mulhall, "Wtitgenstein and Heidegger: Orientations to the Ordinary", European Journal of Philosophy 2 (1994).

${ }^{4}$ No presente contexto, deve entender-se por "explicação" a explicação de tipo causal ou nomológico. Com efeito, existe um outro sentido do termo "explicação", segundo o qual, por exemplo, se explica o significado de um termo mostrando o seu uso. Em relação a este segundo sentido, Wittgenstein não só aceita as explicações como ainda considera que existe uma relação íntima entre significado e explicação, como se verá. 
tuída apenas pela descrição" (PU §109). A filosofia é concebida como uma investigação conceptual e gramatical, cujo objecto é a linguagem no seu uso:

De maneira nenhuma deve a Filosofia tocar no uso real da linguagem; só o pode enfim descrever.

Assim, também não o pode fundamentar.

A Filosofia deixa tudo ser como é. (PU §124)

Todảvia, ao investigar a linguagem Wittgenstein não se restringe a uma esfera meramente linguística, visto ser sua convicção que a linguagem marca e atravessa toda a nossa experiência; tal como ele afirma, "conceber uma linguagem é conceber uma forma de vida" (PU §19). A linguagem pode, legitimamente, servir de fio condutor para as investigações filosóficas. Por este motivo, John Austin, um autor profundamente influenciado pela obra tardia de Wittgenstein, sugeriu a expressão "fenomenologia linguística", em detrimento de outras como "análise da linguagem", para caracterizar o seu projecto filosófico e deixar claro que o estudo da linguagem transcende o domínio estritamente verbal, englobando o estudo das realidades de que se fala. ${ }^{5}$

A concepção da filosofia como mera descrição (e descrição da experiência quotidiana) está associada a uma clara distinção entre as investigações conceptuais, próprias da filosofia, e as investigações factuais e empíricas, próprias da ciência natural (cf. Z §458). À semelhança da tradição fenomenológica, Wittgenstein rejeita o cientismo, procurando investigar o conhecimento e a intencionalidade à revelia dos métodos das ciências naturais, praticando, por assim dizer, a epoché ou a suspensão da ciência objectiva. Deste modo, afirma que "[n]ós não estamos no domínio das explicações causais e cada explicação dessas soa-nos como trivial” (PG 105), rejeitando explicitamente que o pensamento possa ser reduzido a um processo cerebral (cf. Z §§67-9). A mesma atitude é adoptada no domínio da linguagem: "Não nos interessa uma explicação do modo de actuar [Wirkungsweise] da linguagem como mecanismo psicofísico. Esta explicação é ela própria uma descrição dos fenómenos (da associação, da memória, etc.) na linguagem" (PG 70). Como veremos na quarta secção, este ponto está estreitamente relacionado com o tema wittgensteiniano da universalidade e autonomia da linguagem.

Para além de não estar interessado em seguir o modelo da ciência, Wittgenstein rejeita qualquer abordagem teórica ou sistemática. Deste modo, denuncia a "aspiração à generalidade" ou a "atitude desdenhosa perante o caso particular" como um dos obstáculos principais às investigações ou des-

${ }^{5}$ Cf. "A Plea For Excuses", in Austin, John, Philosophical Papers, Oxford, Oxford University Press, 1979, p. 182. 
crições filosóficas e aponta a influência exercida sobre os filósofos pelos métodos das ciências naturais como uma das fontes da referida aspiração ou atitude:

A nossa aspiração à generalidade tem uma outra fonte principal: o nosso preconceito a favor do método das ciências naturais. [...] Os filósofos têm constantemente os métodos das ciências naturais diante dos olhos e sentem a irresistível tentação de colocar e responder a questões do tipo das ciências da natureza. Esta tendência é a verdadeira fonte da metafísica e conduz o filósofo à obscuridade completa. Gostaria de dizer aqui que nunca pode ser nosso objectivo reduzir algo a algo ou explicar algo. A filosofia é, de facto, "puramente descritiva". (BB 38-9)

Na sua rejeição do cientismo, bem como, de forma mais geral, de qualquer abordagem com carácter sistemático ou teórico, o pensamento de Wittgenstein opõe-se, de forma muito clara, aos programas de naturalização tão em voga no âmbito da filosofia analítica.

Por todas estas razões, não é de estranhar que Wittgenstein tenha chegado a classificar o seu pensamento filosófico como "fenomenologia", o que sucedeu sobretudo no período de redacção das Philosophische Bemerkungen. A escolha de tal designação é perfeitamente compreensível, se tivermos em conta que Wittgenstein e a tradição fenomenológica concebem a filosofia como uma descrição pura da experiência e como uma actividade não só independente da ciência, mas também, de certo modo, mais fundamental do que esta. Se Husserl considerava a fenomenologia como o fundamento das diferentes ciências, porque o conhecimento se funda na consciência, Wittgenstein irá defender que o estudo da gramática, do sistema de regras de uma linguagem, tem uma certa prioridade sobre as investigações empíricas:

A fenomenologia fixa apenas as possibilidades. A fenomenologia seria, portanto, a gramática da descrição daqueles factos sobre os quais a física constrói as suas teorias.

Explicar é mais do que descrever. Mas cada explicação contém uma descrição. (PB §1)

Sendo uma investigação conceptual ou gramatical, a fenomenologia wittgensteiniana tem como objecto não a consciência, mas a gramática (em sentido wittgensteiniano), ou seja, o sistema de regras que preside ao uso das palavras numa determinada linguagem. ${ }^{6} \mathrm{O}$ facto de o substantivo "fenomenologia" ter sido abandonado posteriormente por Wittgenstein não é signifi-

${ }^{6}$ Gérard Guest, em "La Phénomenologie de Wittgenstein” (Heidegger Studies 7 (1991), p. 66), afirma que os fenómenos, segundo Wittgenstein, são a gramática e as regras dos jogos de linguagem e das formas de vida. 
cativo, pois pode ter resultado do desejo de evitar uma confusão com posições filosóficas diferentes da sua, mesmo que algo aparentadas.

A fenomenologia da quotidianidade de Wittgenstein tem claras correspondências na obra de Heidegger. Em Ser e Tempo, Heidegger não oferece uma argumentação detalhada, mas sim umá descrição fiel da nossa experiência do mundo. Um dos principais resultados das investigações fenomenológicas oferecidas em Ser e Tempo é a rejeição da concepção tradicional do sujeito e da consciência. Heidegger substitui, com efeito, o termo "sujeito" pelo termo "Dasein" (que significa, literalmente, "ser-aí"); em oposição à imagem tradicional do sujeito como uma esfera autónoma, o Dasein é constitutivamente um ser-no-mundo, ou seja, é inconcebível sem o seu mundo, sem o seu contexto particular de práticas culturais e sociais. Por este motivo, e ainda segundo Heidegger, a mundanidade (Weltlichkeit) é um existencial (Existenzial), ou seja, um traço da constituição ontológica do próprio Dasein (cf. SZ. 64). Dado que uma descrição correcta da condição humana mostra que não é possível estabelecer uma distinção rígida entre uma esfera interior e o ambiente exterior, entre o que cada um de nós é e as suas práticas, a concepção moderna do sujeito e, com ela, o problema da existência do mundo exterior são dissolvidos: "A clarificação do ser-no-mundo mostrou que um mero sujeito sem objecto não 'é' de forma imediata nem nunca é dado" (SZ 116; cf. SZ 205). Com efeito, nós somos, como Heidegger diz, aquilo que fazemos (cf. SZ 239), e as nossas práticas consistem em lidar com pessoas e com coisas. Assim sendo, a existência humana é inconcebível sem um mundo exterior.

Em suma, Wittgenstein e Heidegger, partindo de uma fenomenologia da quotidianidade, defendem que a base do conhecimento e da existência humana é constituída pela nossa forma de vida ou pelo ser-no-mundo, não pela mente ou pela consciência. Deste modo, afastam-se, num ponto fundamental, da ortodoxia fenomenológica, na medida em que se desinteressam do estudo da consciência. Com efeito, ambos se recusam a pôr o mundo ou a forma de vida entre parênteses. Dizia Heidegger que a consciência se fundamenta no Dasein, no ser-no-mundo, e não vice-versa, o que constitui uma inversão do projecto fenomenológico originariamente proposto por Husserl. ${ }^{7}$ De forma análoga, Wittgenstein propõe uma concepção do conhecimento e da linguagem baseada em factores pragmáticos e sociais, não em estados mentais. Heidegger e Wittgenstein coincidem, assim, na sua oposição ao "mito da interioridade": o Dasein é, constitutivamente, um ser-no-mundo, e segundo Wittgenstein " $[\mathrm{u}] \mathrm{m}$ processo interior necessita de critérios exteriores" (PU §580). ${ }^{8}$ Como se verá adiante, o suposto mundo interior da

\footnotetext{
${ }^{7}$ Cf. M. Heidegger, Seminare (Gesamtausgabe, Bd. 15), Frankfurt/M, V. Klostermann, 1986, pp. 379-80.

${ }^{8}$ A rejeição do mito da interioridade atinge indirectamente o próprio behaviorismo. Se a distinção entre o interior e o exterior não é válida, não são correctas as doutrinas que subordi-
} 
consciência está inelutavelmente contaminado por algo que não é interior: a linguagem.

\section{O significado hermenêutico da reflexão wittgensteiniana sobre a certeza}

A filosofia tardia de Wittgenstein sublinha, à semelhança da hermenêutica, o papel fundamental desempenhado pelo background de inteligibilidade subjacente às nossas práticas quotidianas e à linguagem corrente. A reflexão wittgensteiniana sobre o conceito de certeza contém preciosas indicações a este respeito. Nas Investigações Filosóficas, Wittgenstein propôs uma abordagem terapêutica dos problemas filosóficos, de acordo com a qual nós "reconduzimos as palavras do seu emprego metafísico ao seu emprego quotidiano" (PU §116). Em Da Certeza, Wittgenstein oferece uma ilustração exemplar desta concepção da filosofia no contexto de uma descrição da gramática ou uso dos termos "dúvida" e "saber".

No tocante ao primeiro ponto, a sua descrição do jogo da dúvida é uma réplica notável à ideia céptica de uma dúvida universal. Se observarmos o uso linguístico corrente, reparamos que a dúvida requer razões e deve ser relevante na prática. Por conseguinte, podemos ignorar muitas dúvidas possíveis. Além disso, "[o] próprio jogo da dúvida pressupõe a certeza" (ÜG $\S 115)$. Três razões podem ser invocadas em defesa desta afirmação. Em primeiro lugar, a dúvida seria inexprimível se não estivéssemos certos de nenhum significado linguístico. Em segundo lugar, a certeza semântica pressupõe a certeza de pelo menos alguns factos; questionar a verdade de certas frases (como, por exemplo, "Isto [a minha mão] é uma mão") denota ignorância semântica. ${ }^{9}$ Em terceiro lugar, a dúvida envolve a possibilidade de testes, mas os testes só são possíveis com base em pressuposições que se esquivam à dúvida. Tal como diz Wittgenstein, "as perguntas que formulamos e as nossas dúvidas dependem do facto de certas proposições estarem isentas de dúvida, serem como que dobradiças em volta das quais as dúvidas giram.” (ÜG §341)

Existem, assim, proposições situadas para além da dúvida, mas serão elas objecto de saber ou de conhecimento? Moore, o filósofo que inspirou as

nam os processos exteriores aos interiores (mentalismo) ou os interiores aos exteriores (behaviorismo). É certo que Wittgenstein, à semelhança dos behavioristas, só se interessa pelo comportamento observável, mas aborda-o a partir de uma perspectiva diferente: não do ponto de vista de uma psicologia empírica, mas do ponto de vista de uma investigação gramatical orientada para a descrição de regras e critérios dos jogos de linguagem.

${ }^{9}$ Cf. ÜG $\$ 114$ ("Quem não tiver a certeza de facto nenhum também não pode ter a certeza do significado das suas palavras") e PU $\$ 381$ ("Como é que sei que esta cor é vermelha? Uma resposta seria: 'Eu aprendi português'”). 
reflexões de Wittgenstein sobre a certeza, afirmava saber com certeza um grande número de proposições ou, como ele lhes chamava, "truísmos óbvios"; proposições como "aqui está uma mão" ou "a terra já existia muitos anos antes do meu nascimento". Wittgenstein concorda que se pode ter a certeza de tais proposições (certezas do senso comum, bem como truísmos científicos e factos biográficos), mas nega que elas possam ser objecto de conhecimento. Wittgenstein clarifica este ponto ao descrever a gramática (no sentido wittgensteiniano) do verbo "saber", o seu uso real em contextos práticos ou quotidianos e depurado de teorias ou construções filosóficas. É fácil mostrar que, em tais contextos, só usamos o verbo "saber" quando faz sentido pedir e dar razões ou justificações, quando o erro e a dúvida são possíveis. Sucede, porém, que as nossas crenças e proposições mais fundamentais não preenchem tais requisitos; como são simultaneamente indubitáveis e injustificáveis, encontram-se também para além do conhecimento, razão pela qual Wittgenstein estabelece uma diferença fundamental entre certeza e saber.

Esta noção de proposições-dobradiças, como são habitualmente designadas, ou de proposições que são ponto assente (feststehende Sätze; cf. ÜG $\S \S 151-2)$, é de um enorme interesse hermenêutico, pois remete para a noção hermenêutica de pré-compreensão, enquanto horizonte de inteligibilidade que é condição de possibilidade do sentido e da nossa experiência. Algumas caracterizações que Wittgenstein oferece de tais proposições básicas evocam de forma muito nítida a noção gadameriana de preconceito. Eis um exemplo claro:

Uma asserção [Behauptungssatz] susceptível de funcionar como uma hipótese não poderá ser também utilizada como fundamento para a pesquisa e acção? [...] É simplesmente assumida como um truísmo, nunca posta em causa, até mesmo talvez nunca formulada. (ÜG §87)

Deste modo, as nossas certezas constituem uma determinada imagem do mundo (Weltbild) ou até, como Wittgenstein refere, uma mitologia. O uso do termo "mitologia" ilustra o facto de a nossa imagem do mundo não poder ser justificada ou apoiada por argumentos, porque é aquilo que torna possível o jogo da justificação e da argumentação: "Mas eu não obtive a minha imagem do mundo por me ter convencido da sua justeza, nem a mantenho porque me convenci da sua justeza. Pelo contrário, é o quadro de referências herdado que me faz distinguir o verdadeiro do falso" (ÜG §94). Importa, porém, sublinhar que o papel fundamental de certas proposições ou crenças não é explicado por um processo ou mecanismo epistémico, mas pela sua conexão íntima com as nossas práticas; por outras palavras, é a forma de vida que determina aquilo que é, para nós, indubitável. Tal como Wittgenstein afirma: 
Mas a fundamentação, a justificação da evidência tem um fim - mas o fim não é o facto de certas proposições se nos apresentarem como sendo verdadeiras, isto é, não se trata de uma espécie de ver da nossa parte; é o nosso agir [Handeln] que está no fundo do jogo de linguagem. (ÜG §204)

Mas o fim [da fundamentação] não é o pressuposto não fundamentado, mas sim o modo de agir não fundamentado [unbegründete Handlungsweise]. (ÜG §110)

Aqui se exprime com clareza o carácter prático da certeza. É a nossa forma de vida, o nosso treino social ou as nossas práticas que constituem as fundações do conhecimento. Dado que a forma de vida é o horizonte último de inteligibilidade e constitui o espaço das razões e justificações, ela própria não pode ser justificada. Deste modo, afirma-se que "[n]a raiz da crença [Glaube] fundamentada encontra-se uma crença não fundamentada" (ÜG §253). E por "crença não fundamentada" deve entender-se não uma crença em sentido vulgar, sujeita a discussão, teste e justificação, mas uma certeza prática, uma certeza sem a qual a prática a que ela se encontra associada se dissolveria. $\mathrm{Na}$ base do conhecimento humano e da intencionalidade está, por conseguinte, uma dimensão pragmática e não propriamente epistémica. Como, por outro lado, as nossas práticas e a nossa imagem do mundo mudam no decurso do tempo, as fundações do conhecimento são instáveis: "A mitologia pode regressar a um estado de fluidez, o leito do rio dos pensamentos pode desviar-se." (ÜG §97)

A reflexão wittgensteiniana sobre a certeza exibe importantes afinidades com a concepção heideggeriana da verdade em Ser e Tempo. De acordo com a tradição, a verdade é uma propriedade de asserções ou proposições, mas Heidegger entende que a verdade proposicional é apenas o ponto de partida para uma análise do fenómeno da verdade, ou seja, que a verdade proposicional está enraizada numa dimensão mais fundamental da verdade: a manifestação dos entes. Tal como afirma Heidegger, um enunciado é verdadeiro se "descobre o ente em si mesmo" (SZ 218). Ele designa esta dimensão da verdade como "descoberta" (ou estado-de-descoberto; Entdecktheit). Mas esta não é ainda a última palavra. Com efeito, a manifestação dos entes requer um espaço de manifestação dos entes ou, para utilizar a terminologia idiossincrática de Heidegger, uma "abertura" (ou estado-de-aberto; Erschlossenheit), que constitui o nível mais fundamental na análise da verdade. A abertura, enquanto verdade originária, é, por um lado, uma dimensão quase-transcendental constituída pela estrutura da temporalidade (que é o tema dos últimos capítulos de Ser e Tempo) e, por outro lado, uma dimensão pragmática, relativa ao contexto de práticas sociais e projectos humanos no seio do qual os entes se revelam e os juízos se tornam possíveis.

Podemos, assim, decifrar a afirmação heideggeriana de que o Dasein "está na verdade" (SZ 221). Tal significa que a "abertura" (como horizonte 
de inteligibilidade dos entes) pertence essencialmente à constituição ontológica do Dasein e proporciona um acesso real aos entes. Porque tal acesso é limitado e parcial, Heidegger acrescenta que a não-verdade pertence essencialmente à verdade. Todavia, a ideia céptica de erro maciço ou de dúvida universal não é aceitável do ponto de vista da fenomenologia da quotidianidade de Heidegger, tal como não o era para Wittgenstein. Mesmo de forma distorcida e inadequada, as nossas práticas quotidianas dão-nos um acesso aos entes. Além disso, o nosso comportamento e as nossas investigações devem necessariamente basear-se num vasto número de certezas práticas que constituem o nosso background de inteligibilidade. Tal background é normalmente imune à dúvida e é constituído por normas, crenças e pressupostos aparentemente evidentes ou naturais; selbstverständlich, como Heidegger frequentemente afirma. ${ }^{10} \mathrm{O}$ peso do contexto prático, social e quotidiano é descrito em termos nos quais Wittgenstein facilmente se reconheceria:

No Dasein, estabeleceu-se já em cada caso este conjunto de interpretações [Ausgelegtheit] da conversação corrente [Gerede]. [...] O Dasein nunca consegue subtrair-se a este conjunto quotidiano de interpretações, no qual ele cresce de imediato. Nele, a partir dele e contra ele, realiza-se toda a genuína compreensão, interpretação e comunicação, redescoberta e reapropriação. (SZ, p. 169)

Este ponto articula-se com a análise heideggeriana do modo de vida impessoal e anónimo, aquilo a que Heidegger chama "das Man" e que se poderia traduzir por "o impessoal". Esta noção, que se refere à inteligibilidade pública ou média e ao seu poder sobre as nossas vidas, é um traço estrutural do Dasein, visto que este se encontra normalmente dominado por práticas e normas comunitárias. Deste modo, assemelha-se fortemente à noção wittgensteiniana de forma de vida. ${ }^{11}$ É verdade que Heidegger distingue entre inautenticidade e autenticidade, entre a aceitação passiva e impessoal de padrões comunitários e a reinterpretação pessoal do mundo e da existência, mas nem por isso a autenticidade deixa de estar condicionada pelo contexto histórico e social, pela inteligibilidade média; ela não é uma anulação, mas sim uma modificação da quotidianidade (cf. SZ 179).

Em suma, Heidegger (em Ser e Tempo) e Wittgenstein (na sua obra tardia) tomaram plena consciência das condições pragmáticas do conhecimento e da intencionalidade e concentraram a sua atenção numa dimensãó absolu-

${ }^{10}$ É sintomático que Wittgenstein utilize o mesmo termo para caracterizar as nossas certezas básicas; assim, afirma que a nossa imagem do mundo é a fundação natural ou evidente (selbstverständliche Grundlage) das nossas investigações (cf. ÜG §167).

1 Ver, a este respeito, John Haugeland, "Heidegger On Being a Person", Nous 16 (1982), p. 17. 
tamente fundamental de práticas linguisticamente articuladas, que é condição de possibilidade das nossas crenças, dúvidas e justificações. Uma dimensão situada, normalmente, para além da dúvida e da justificação.

\section{Uso e significado}

Na sua obra tardia, Wittgenstein abordou o problema do significado a partir de uma perspectiva claramente oposta às abordagens tradicionais. Ao longo da história da filosofia, foi frequente a desvalorização epistemológica e ontológica da linguagem, i.e., a subordinação desta última à ordem do pensamento ou à estrutura da realidade. As palavras eram entendidas como signos que remetiam para representações mentais, conceitos ou objectos, e a linguagem deveria limitar-se a exprimir o pensamento e espelhar a realidade. Apesar de, no Tractatus, se reconhecer a importância da linguagem para a filosofia (a qual era, aí, concebida como "crítica da linguagem"), a verdade é que Wittgenstein permaneceu, de certo modo, refém da concepção tradicional da linguagem na referida obra, pois continuou a conceber a linguagem como representação ou espelho da realidade.

Em consonância com o projecto filosófico de uma descrição da quotidianidade, Wittgenstein cedo se desinteressou da aplicação de métodos formais ao estudo da linguagem, optando por uma aceitação incondicional da linguagem "habitual", "natural", "quotidiana" ou "normal”, como ele próprio a qualifica em diferentes ocasiões. Enquanto no Tractatus se defendia uma teoria verocondicional do significado, de acordo com a qual o sentido de uma proposição seria dado pelas suas condições de verdade, ${ }^{12}$ Wittgenstein irá posteriormente desenvolver uma concepção do significado como uso: "Para uma grande classe de casos - embora não para todos - do emprego da palavra 'significado' [Bedeutung] pode dar-se a seguinte explicação: o significado de uma palavra é o seu uso na linguagem" (PU §43; cf. PU §432, PU 563 e BB 20). Note-se que esta ênfase no uso é perfeitamente natural de um ponto de vista fenomenológico: se queremos dirigir um olhar não contaminado por teorias ou ideias pré-recebidas para "as próprias coisas", tal injunção, no caso da linguagem, tem como resultado a descrição da linguagem no seu uso real, quotidiano.

Em estreita ligação com o elo que é estabelecido entre significado e uso, está a relação entre significado e explicação do significado: "O significado [Bedeutung] da palavra é aquilo que a explicação do significado explica" (PU §560; cf. BB 15 e PG 59). Com efeito, as explicações do significado são, basicamente, esclarecimentos do modo como se usa ou se deve

${ }^{12}$ Cf. Tractatus logico-philosophicus 4.024: “Compreender uma proposiç̃̃o quer dizer, saber o que acontece, se ela é verdadeira." 
usar uma palavra, expressão ou frase. Uma explicação, neste sentido, repousa, em última instância, nas aplicações concretas dos termos: "Pois nesta explicação [de um conceito] mostrar-se-á o que o meu conceito é [...]. Eu explicaria o conceito através de exemplos. - Portanto, o meu conceito vai até onde os meus exemplos vão" (PG 112).

A concepção do significado como uso e o primado atribuído ao exemplo em detrimento de princípios gerais subvertem a relação tradicionalmente estabelecida entre significado e uso. Em vez de pressupor a existência de significados e conteúdos conceptuais à partida para, em seguida, explicar o uso dos termos e expressões, Wittgenstein mostra que é possível inverter a ordem da explicação e mostrar a constituição dos significados e dos conteúdos conceptuais a partir do uso e das regras linguísticas. Assim sendo, uma alteração ao nível do uso de uma expressão é necessariamente uma alteração do significado. A ideia de significados ideais aos quais os usos linguísticos se deveriam adequar é desprovida de sentido, pois os significados não são entidades autónomas, subsistentes, pairando acima das expressões verbais (cf. PU §329), mas uma função da rede linguística ou do jogo de linguagem. A concepção wittgensteiniana do significado como uso opõe-se frontalmente à reificação dos significados, à ideia de "corpos semânticos" ou Bedeutungskörper (cf. PU §559 e PG 54). Além disso, rejeita qualquer subordinação da dimensão pragmática da linguagem à sua dimensão sintáctica e semântica, afastando-se, assim, do positivismo lógico, que valorizava claramente os estudos sintácticos e semânticos. A dimensão pragmática ou social da linguagem, longe de ser parasitária relativamente às outras duas, é absolutamente fundamental, pois é no seu âmbito que o significado das palavras e o sentido das frases se forma e se constitui.

A noção de jogo de linguagem ("o todo formado pela linguagem com as actividades com as quais ela está entrelaçada"; PU §7) é introduzida precisamente com o intuito de "realçar o facto de que falar uma língua é uma parte de uma actividade ou de uma forma de vida" (PU §23); noutros termos, para frisar que o nosso discurso adquire sentido através do resto das nossas acções (cf. ÜG §229). A concepção do significado como uso e a noção de jogo de linguagem exprimem de forma clara a oposição às teorias tradicionais do significado: teorias referenciais ingénuas, segundo as quais o significado de uma palavra é o objecto por ela designado; teorias de tipo mentalista, que associam o significado das expressões a estados mentais; e ainda teorias platonistas, que procuram explicar o significado postulando entidades ideais ou abstractas.

Também Heidegger e Gadamer se opṍem à reificação do sentido, mostrando como o sentido do interpretandum é indissociável do contexto da interpretação e varia com este. Além disso, ao conceber o significado como uso, Wittgenstein pretende chamar a atenção para o carácter não sistematizá- 
vel nem formalizável do significado, ${ }^{13}$ o que constitui mais um ponto de contacto com a hermenêutica. Com efeito, a concepção do significado como uso não é mais uma teoria do significado, mas uma recusa de teorias do significado, i.e., de uma abordagem do problema do significado que envolva construções sistemáticas e idealizações dos fenómenos. O recurso ao uso é análogo ao apelo fenomenológico de regresso "às próprias coisas", razão pela qual também é legítimo aplicar à obra tardia de Wittgenstein o rótulo de "fenomenologia linguística".

\section{A universalidade e autonomia da linguagem}

Sublinhe-se, porém, que a assimilação do significado ao uso (bem como a comparação da linguagem com uma caixa de ferramentas; cf. PU §11) não se deve confundir com uma concepção meramente instrumentalista da linguagem (cf. PG 190); pelo contrário, Wittgenstein vê na linguagem natural o horizonte universal da experiência humana. Esta defesa da universalidade da linguagem é um dos aspectos fundamentais do pensamento de Wittgenstein e um dos que mais o aproxima de autores como Heidegger ou Gadamer. Já no Tractatus (na proposição 5.6) se tinha afirmado que os "limites da minha linguagem significam os limites do meu mundo", mas na obra tardia de Wittgenstein este tema é declinado de modo significativamente diferente, na medida em que a análise da estrutura lógica da linguagem é substituída por uma análise do enraizamento da linguagem nas nossas actividades e na nossa forma de vida. O carácter unitário e unívoco de uma linguagem feita "do mais puro cristal” (PU §97) dá lugar à fragmentação da linguagem numa multiplicidade irredutível de jogos de linguagem estreitamente ligados a um determinado contexto prático e abertos à evolução. Qualquer estratégia de colonização da linguagem natural por parte de linguagens formais é liminarmente recusada por Wittgenstein, o que o aproxima claramente da tradição fenomenológico-hermenêutica. ${ }^{14}$

Wittgenstein advoga aquilo a que, recorrendo a uma expressão de Rorty, poderíamos chamar a tese da ubiquidade da linguagem, ${ }^{15}$ ou seja, a

${ }^{13}$ Veja-se, a este respeito, Warren Goldfarb, "I Want You to Bring Me a Slab", Synthese 56 (1983).

${ }^{14}$ Pode traçar-se, neste contexto, um paralelo com Husserl: tal como este, em particular na última fase da sua obra, denunciou o facto de a concepção científica do mundo e da experiência se basear, por um lado, em idealizações feitas a partir do mundo da vida e de confundir, por outro lado, a realidade com a representação científica da realidade, assim também Wittgenstein salienta que o estudo da linguagem baseado no modelo das linguagens formais tende a esquecer que estas têm a sua génese na linguagem natural. As "idealidades", filhas do mundo da vida, regressam para o subjugar.

15 Cf. Richard Rorty, Consequences of Pragmatism, Minneapolis, University of Minnesota Press, 1982, p. xix. 
ideia de que a linguagem atravessa toda a nossa experiência, não podendo ser explicada por ou reduzida a uma dimensão não linguística. Efectivamente, e à semelhança do pensamento hermenêutico, Wittgenstein rejeita as diferentes estratégias reducionistas que procuram explicar a linguagem a partir de dimensões não linguísticas: representações mentais, estimulações do sistema nervoso, objectos físicos ou o esquema estímulo/resposta. Tal como ele afirma, "cada forma de tornar compreensível uma língua já pressupõe uma língua” (PB 54). A linguagem, porque preside a toda a explicação (entendida como subsunção de fenómenos sob leis naturais ou hipóteses causais), não pode ela própria ser explicada (no sentido referido). $\mathrm{O}$ facto de as expressões linguísticas serem usadas ou aplicadas desta ou daquela maneira é o nec plus ultra da análise. Como diz Wittgenstein: "O difícil aqui não é escavar até ao fundo [Grund], mas reconhecer como fundo o fundo que está diante de nós." ${ }^{16}$ As dimensões que serviriam supostamente de base ou fundamento da linguagem revelam-se, após análise, como estando abrangidas pela rede da linguagem.

Este tema da ubiquidade ou universalidade da linguagem pode ser tratado a partir de duas perspectivas, a saber: a partir da relação entre linguagem e pensamento, bem como a partir da relação entre linguagem e realidade. Comecemos pela primeira perspectiva. A crítica wittgensteiniana da reificação dos significados (i.e., da noção de corpos semânticos) está associada a uma crítica do pensamento como algo de anterior à ou independente da linguagem. Wittgenstein opõe-se, em particular, à tese segundo qual falar consistiria em utilizar uma linguagem verbal para traduzir uma linguagem espiritual (geistig; cf. BB 70 e Z §191). Tal mitologia está latente em expressões de uso comum como "ter uma ideia na mente" ou "encontrar a expressão correcta para um pensamento". É como se a relação entre o pensamento e a linguagem fosse comparável à relação existente entre a melodia e a letra de uma canção; do mesmo modo que podemos entoar uma melodia ignorando a letra, também poderíamos pensar sem palavras (cf. BB 72). Todavia, tal concepção não é uma descrição correcta da nossa experiência enquanto seres pensantes e falantes. Wittgenstein procede, a este respeito, more phaenomenologico; em conformidade com a sua exortação "não penses, olha" (PU §66), desafia o leitor a tentar pensar o conteúdo da frase "amanhã irá provavelmente chover" sem usar palavras, sejam elas ditas em voz alta ou apenas para si próprio (cf. BB 72). A tarefa é hercúlea... Somos induzidos a concluir que "a experiência do pensar só pode ser a experiência do dizer" (BB 73). Esta conclusão pode ser contestada do ponto de vista da psicologia cognitiva, pois é possível atribuir a seres não linguísticos certas formas rudimentares de raciocínio. Todavia, ultrapassado esse nível rudimentar, a

${ }^{16}$ L. Wittgenstein, Bemerkungen über die Grundlagen der Mathematik (Werkausgabe, Bd. 6),

Frankfurt am Main, Suhrkamp, 1984, p. 333. 
posição de Wittgenstein sobre o carácter linguístico do pensamento afigura-se plausível. Deste modo, sempre que alguém afirma que ainda não encontrou as palavras certas para exprimir aquilo que quer dizer, será lícito afirmar que tal pessoa está apenas a reconhecer, de forma imprecisa, que ainda não sabe ao certo o que quer dizer. A seguinte passagem aponta precisamente neste sentido:

O que é dito só se pode explicar através da linguagem, por isso não se pode explicar a própria linguagem, neste sentido.

A linguagem tem que falar por si própria.

Pode dizer-se: A intenção surge a partir da linguagem [Die Meinung fällt aus der Sprache heraus], pois o que uma frase quer dizer [meint] é dito de novo através de outra frase. (PG 40-1) ${ }^{17}$

Assim sendo, torna-se claro que a intencionalidade tem um carácter não apenas pragmático, mas também linguístico. A relação tradicional entre linguagem e realidade é igualmente subvertida pela tese da universalidade da linguagem. Entendia-se, frequentemente, que a linguagem deveria funcionar como um mero espelho de uma realidade totalmente autónoma e independente, sendo exigido à linguagem que representasse correctamente tal realidade. Mas as dificuldades inerentes a tal concepção são óbvias. Com efeito, não é possível testar a concordância da linguagem com a realidade, visto que nos falta um critério ou um ponto de vista exterior à linguagem que permitisse avaliar a sua adequação à realidade. Wittgenstein expressa este ponto de forma muito clara: "A conexão entre 'linguagem e realidade' é feita através das explicações verbais [Worterklärungen], - as quais pertencem à gramática [Sprachlehre], de modo que a linguagem permanece em si fechada, autónoma" (PG 97). Esta tese da autonomia da linguagem significa que a linguagem não se encontra subordinada a nenhuma dimensão pré-linguística; nem à ordem do pensamento, nem à estrutura da realidade. Com efeito, qualquer justificação de uma gramática ou forma de representação nos termos de um acordo com a realidade está condenada ao insucesso, na medida em que tal justificação pressupõe uma determinada descrição daquilo que é representado, o que por seu turno pressupõe já uma determinada gramática ou sistema de descrição (cf. PB 55 e PG 186). A linguagem configura a realidade:

O que parece ter de existir, pertence à linguagem. É um paradigma no nosso jogo de linguagem, uma coisa com a qual se podem efectuar comparações. (PU §50)

17 Tal como diz Michael Zimmermann: "O pensamento é uma função da frase, e não ao contrário" (M. Zimmermann, Wittgensteins sprachphilosophische Hermeneutik, Frankfurt am Main, V. Klostermann, 1975, p. 136). 
A essência manifesta-se na gramática. (PU §371)

Que espécie de objecto uma coisa é, di-lo a gramática. (A teologia como gramática). (PU §373)

Para se apreciar o sentido destas passagens, importa, antes de mais, aprofundar a noção wittgensteiniana de gramática. Uma gramática é um sistema de regras linguísticas que, por um lado, determina a nossa representação e descrição da realidade, constituindo os carris do pensamento e acção (cf. Z §375), e que, por outro lado, é afectada pelos resultados da investigação empírica, bem como por desenvolvimentos ao nível da forma de vida. Dada a conjunção destes dois aspectos, ela é, nas palavras de Michael Zimmerman, um "a priori fáctico do conhecimento"; é facticamente necessária, mas por princípio contingente. ${ }^{18}$

Das regras gramaticais não se pode dizer que sejam verdadeiras ou falsas; na medida em que fixam o uso correcto e, por conseguinte, o significado das palavras, são, antes, condição de possibilidade das nossas descrições e justificações, bem como da formulação de juízos verdadeiros ou falsos. Nos termos da Philosophische Grammatik, dir-se-ia que as regras gramaticais estão para os juízos que autorizam como a unidade de medida está para as medições concretas; o resultado de uma medição pode ser verdadeiro ou falso, mas não a escolha da unidade de medida (cf. PG 185). Outra analogia é dada pela noção de jogo: as regras gramaticais estão para as enunciações linguísticas como as regras de um jogo estão para as acções que se praticam no âmbito do jogo. Não são descrições da realidade, mas condições de possibilidade de tais descrições. É neste sentido que Wittgenstein afirma que "a gramática não presta contas à realidade" (PG 184).

Assim sendo, e retomando as passagens acima transcritas, torna-se mais claro em que medida a gramática fixa a "essência" dos objectos ou "o que tem de existir". A comparação entre a gramática e a teologia é, a este respeito, muito sugestiva. Do mesmo modo que, numa perspectiva teológica, a realidade reflecte ideias ou essências presentes no entendimento divino, na perspectiva de Wittgenstein a realidade é configurada por regras e categorias linguísticas, pelo sistema de descrição associado a uma determinada gramática.

O tema da universalidade da linguagem é também fundamental na obra de Heidegger (sobretudo depois de Ser e Tempo) e de Gadamer, pois ambos consideram a linguagem como o meio ou horizonte universal da existência humana e da compreensão. Deste modo, Heidegger não hesitou em qualificar a linguagem como a "casa do ser" e em afirmar que "[s]ó onde há linguagem há mundo". ${ }^{19}$ À semelhança de Wittgenstein, que reflectiu sobre o

${ }^{18}$ Cf. Michael Zimmermann, op. cit., pp. 13 e 248.

19 Erläuterungen zu Hölderlins Dichtung (Gesamtausgabe, Bd. 4), Frankfurt am Main, V. Klostermann, 1991, p. 38. 
modo como a gramática determina a nossa representação do mundo e o nosso pensamento, também Heidegger alerta para o primado da linguagem sobre o falante; não só afirma que a linguagem nos precede constantemente,$^{20}$ como chega a defender que é a linguagem, e não propriamente o homem, que fala: "Pois, no sentido próprio, é a linguagem que fala. O homem fala apenas na medida em que responde à linguagem, em que escuta o seu apelo."

Gadamer partilha também a concepção da linguagem como horizonte de toda a experiência. No âmbito de uma análise da concepção humboldtiana da linguagem como formadora do pensamento e portadora de uma visão do mundo, Gadamer defende que o mundo se encontra articulado linguisticamente, de modo que é com base na linguagem que o homem tem um mundo (cf. WM 446-7). Por outras palavras, “[o] ser que pode ser compreendido é linguagem" (WM 478). Convirá alertar para o facto de Gadamer, com esta última frase, não pretender afirmar que o ser seja linguagem (algo que Wittgenstein rejeitaria), mas tão-só chamar a atenção para o carácter inevitavelmente linguístico da compreensão e da experiência humana do mundo (algo com que Wittgenstein concordaria). Também relevante, a este respeito, é o modo como Gadamer equaciona a relação entre pensamento e linguagem. Como é natural, ao aderir à tese da universalidade da linguagem, Gadamer não pode atribuir à linguagem um estatuto de inferioridade em relação ao pensamento; com efeito, a linguagem "não se limita à mera manifestação do pensado. Antes pelo contrário, o próprio pensamento só ganha a sua existência determinada ao ser apreendido em palavras." 22 Também neste ponto, o acordo com Wittgenstein é total. Com base no carácter linguístico do pensamento, da compreensão e da experiência do mundo, Gadamer pode, facilmente, criticar a ideia de um "sentido em si" (WM 477) e de um "mundo em si" (WM 451).

Uma vez que a linguagem é o horizonte inevitável da compreensão e do conhecimento, Heidegger e Gadamer consideram que ela não pode ser tratada como um mero objecto entre outros. Esta linha de reflexão converge com a renúncia wittgensteiniana a investigações empíricas sobre a linguagem e com a rejeição de qualquer tentativa de explicar a linguagem a partir de uma perspectiva que lhe seja exterior; a linguagem é um pressuposto incontornável de toda a investigação, incluindo a investigação sobre a linguagem.

Importa ainda salientar que o tema da universalidade da linguagem traz implícito o reconhecimento do círculo hermenêutico. Se a linguagem e a inteligibilidade que ela comporta são condição da experiência humana do

${ }^{20}$ Cf. Unterwegs zur Sprache (Gesamtausgabe, Bd. 12), Frankfurt am Main, V. Klostermann, 1985 , p. 168.

${ }^{21}$ Vorträge und Aufsätze, Pfullingen, Verlag Günther Neske, 1954, p. 190.

${ }^{22}$ Neuere Philosophie I (Gesammelte Werke 3), Tübingen, J.C.B. Mohr, 1987, p. 82. 
mundo, todo o esforço de compreensão assenta numa pré-compreensão presente na linguagem e nas práticas a ela associadas.

\section{A compreensão como capacidade prática}

O problema da compreensão assume especial destaque na obra tardia de Wittgenstein. Rejeitada a noção de "corpos semânticos", a compreensão não pode ser entendida como uma apreensão de entidades autónomas e subsistentes. Tal como o significado de uma palavra é aquilo que a explicação da referida palavra explica, e não algo que transcenda as nossas explicações, também existe uma relação interna entre compreensão e significado.

Dado que o significado é determinado pelo uso e que o uso obedece a regras, o problema da compreensão do significado está estreitamente relacionado com a questão de saber como se segue uma regra, razão pela qual esta última questão ocupa uma posição central nas Investigações Filosóficas. Há três pontos, em particular, que importa destacar na reflexão wittgensteiniana sobre as regras.

Em primeiro lugar, Wittgenstein sublinha que nenhum facto relativo ao meu comportamento passado determina de forma unívoca uma regra. Com efeito, qualquer conjunto finito de comportamentos linguísticos pode ser explicado de acordo com $n$ regras diferentes, do mesmo modo que a mesma sucessão aritmética pode ser prosseguida de diferentes modos, de acordo com $n$ funções diferentes.

Em segundo lugar, e em oposição ao mentalismo, Wittgenstein nega que seguir regras consista num processo mental. Uma objecção de fundo contra uma abordagem de tipo mentalista consiste no facto de as representações mentais não determinarem de forma linear a sua aplicação ou interpretação. ${ }^{23}$

Em terceiro lugar, Wittgenstein rejeita que a conexão entre a regra e a sua aplicação possa ser estabelecida mediante interpretações da regra em questão, porque o recurso a interpretações engendra uma regressão infinita: se o sentido de uma regra é dado por uma determinada interpretação, tal interpretação ou formulação deve, por seu turno, ser interpretada, e assim sucessivamente. Por isso, Wittgenstein afirma que "cada interpretação está, juntamente com o que é interpretado, suspensa no ar e não pode servir-lhe de apoio. As interpretações por si não determinam o sentido." (PU §198) Mais precisamente, somos forçados a concluir que "existe uma concepção de uma regra que não é uma interpretação" (PU §201).

${ }^{23}$ Por exemplo, a imagem de um cão castanho pode ser associada aos termos "cão", "animal", "mamífero", "castanho", etc. 
E em que é que consiste tal concepção? Wittgenstein não oferece uma resposta muito precisa, mas deixa claro que seguir regras deve ser entendido simplesmente como uma prática, ou uma capacidade prática, e que nada de exterior ou de transcendente às práticas pode explicar o modo como segui-' mos uma regra. Deste modo, Wittgenstein sublinha a importância dos processos de adestramento, pelos quais somos ensinados a reagir a certas situações de determinado modo; a compreensão pode suceder frequentemente mediante explicações, mas o "fundamento de toda a explicação é o adestramento [Abrichtung]" (Z 419; cf. PU §5 e 198). De forma análoga, afirma que os conceitos são explicados, em última instância, "por meio de exemplos e de exercícios" (PU §208). Wittgenstein procura contrariar a nossa tendência para desvalorizar o exemplo ou o caso particular como meras ilustrações acessórias de princípios gerais:

O que é 'aprender uma regra'? - Isto.

O que é 'fazer um erro' um erro ao aplicá-la? - Isto. E aquilo para que se aponte aqui é algo de indeterminado. (ÜG §28)

Para estabelecer uma prática, não são suficientes regras, também se precisa de exemplos. As nossas regras deixam portas traseiras [Hintertüren] abertas, e a prática tem de falar por si própria. (ÜG §139)

Se seguir uma regra é, como se vê, uma capacidade prática, e não um mero processo mental, então a própria compreensão é uma capacidade prática: "Compreender uma linguagem significa dominar uma técnica" (PU $\S 199)$. Com efeito, se "falar uma língua é parte de uma actividade ou de uma forma de vida" (PU §23), então devemos concluir que "conceber uma linguagem é conceber uma forma de vida” (PU §19). A compreensão só é possível a partir da perspectiva interna de um participante e não a partir da perspectiva externa de um observador.

Ora, a subordinação wittgensteiniana da interpretação à compreensão parece estar em rota de colisão com o pensamento hermenêutico, que tanto valoriza o papel da interpretação, mas uma análise mais atenta poderá esbater o contraste que aqui se esboça. Por um lado, e apesar de Wittgenstein não atribuir à interpretação um papel fundamental, a verdade é que as explicações do significado ou do sentido desempenham um papel hermenêutico inegável: "Não te esqueças de que as palavras têm os significados que lhes demos; e damos-lhes significados através de explicações" (BB 51-2). Esta passagem sugere que o sentido de um texto, por exemplo, não pode ser considerado como algo de independente da nossa interpretação. Por outro lado, e concentrando-nos no caso de Gadamer, a associação entre compreensão e interpretação não deve ser entendida como uma mera identificação, pois também Gadamer reconhece que existe um nível básico da compreensão que dispensa o esforço interpretativo: “Compreender uma língua não é ainda, de 
modo nenhum, uma compreensão real e não inclui nenhum processo interpretativo, sendo, antes, uma operação da vida [Lebensvollzug]. Compreende-se uma língua, na medida em que se vive nela." (WM 388) Gadamer distingue, assim, dois tipos de compreensão: uma que não envolve interpretação, por se manifestar nas "operações da vida"; e a "compreensão real", que parece referir-se aos casos em que procuramos compreender outrem ou um universo cultural estranho. Seria só a este segundo nível que a compreensão envolveria a interpretação. ${ }^{24}$

Importa salientar que a hermenêutica concebe igualmente a compreensão como uma capacidade prática e se opõe ao mentalismo. Heidegger, em Ser e Tempo, entende a compreensão como uma projecção de possibilidades de ser e de agir (SZ §31). Deste modo, a compreensão revela-se como uma competência prática, um know-how, uma capacidade de nos orientarmos no mundo e de participar em determinadas práticas. Ao mesmo tempo, desenvolve uma concepção pragmática da significação, de acordo com a qual as significações linguísticas têm a sua génese na função que os entes desempenham nas nossas práticas (cf. SZ §§14-18). A própria concepção heideggeriana da interpretação como uma "elaboração das possibilidades projectadas na compreensão" é, a este respeito, significativa, pois implica uma rejeição de toda a hermenêutica orientada para a mente do autor. No tocante a Gadamer, sublinhe-se que a sua crítica da concepção da compreensão como "transposição psíquica" (cf., e.g., WM 398) é também uma forma de antimentalismo. Além disso, é possível atribuir-lhe a defesa da perspectiva do participante, dada a sua concepção dialógica da compreensão. Compreender não é reconstituir a mente de outrem, mas abrir-se ao que é dito, com vista a chegar a um entendimento acerca do assunto em questão. Em Gadamer, não há uma análise do papel das práticas quotidianas como se pode encontrar em Heidegger e Wittgenstein, mas há pelo menos um reconhecimento genérico de que "a linguagem pertence à praxis, à convivência humana."25

\section{O problema do relativismo e a fusão de horizontes}

A suspeita de relativismo paira frequentemente sobre a obra de Wittgenstein, Heidegger e Gadamer. Na base de tal suspeita, está a ideia de que a nossa forma de vida ou o nosso contexto prático, social e histórico consti-

\footnotetext{
${ }^{24}$ Ver, a este respeito, Albrecht Wellmer, "Verstehen und Interpretieren", Deutsche Zeitschrift für Philosophie 45 (1997). Wellmer distingue entre uma compreensão performativa, relativa à perspectiva da primeira pessoa e à capacidade prática de seguir regras, e uma compreensão interpretativa, associada à perspectiva da segunda pessoa, ou seja, à compreensão de outrem.

${ }^{25}$ Hans-Georg Gadamer, Kunst als Aussage (Gesammelte Werke 8), Tübingen, J.C.B. Mohr, 1993, p. 343.
} 
tuem a fonte e o limite da inteligibilidade, não sendo susceptíveis de justificação e fundamentação.

Como vimos, Wittgenstein entende, à semelhança do pensamento hermenêutico de Heidegger e de Gadamer, que o nosso background social e histórico de práticas, normas, crenças e certezas configura de antemão a experiência humana e, em particular, as nossas investigações. De tal background pode dizer-se que fixa a "armação [Gerüst] dos nossos pensamentos" (ÜG §211), fornece "os carris fixos sobre os quais todo o nosso pensamento corre" ( $\mathrm{Z}$ 375) e é "o quadro de referências herdado que me faz distinguir o verdadeiro do falso" (ÜG §94). Facilmente se detecta aqui a presença da noção hermenêutica da pré-compreensão, enquanto condição da compreensão de outrem ou base para a projecção do significado das palavras, coisas e situações. Dado que a forma de vida, o contexto prático ou o horizonte histórico constituem a nossa identidade, a acção do background de inteligibilidade não pode ser neutralizada. Tal como, do ponto de vista hermenêutico, não é possível suspender o contexto fáctico da nossa vida ou o nosso horizonte social e cultural, também para Wittgenstein não é possível suspender a nossa forma de vida. Com efeito, se esta é a fonte de toda a inteligibilidade, pôr entre parênteses a forma de vida equivaleria a transgredir os limites da inteligibilidade.

Além disso, na obra tardia de Wittgenstein, o tema da facticidade da linguagem e da forma de vida é associado a uma atitude de resignação e até mesmo de quietismo:

O que tem de ser aceite, o que é dado, pode dizer-se, são as formas de vida. (PU, p. 572)

O nosso erro consiste em procurar uma explicação onde devemos ver os factos como o "fenómeno primordial". Isto é, onde devíamos dizer: este jogo de linguagem joga-se. (PU §654)

Você deve ter em atenção que o jogo de linguagem é, por assim dizer, imprevisível. Quero dizer: não está fundamentado. Não é racional [vernünftig] (ou irracional).

Está aí - tal como a nossa vida. (ÜG §559)

É assim que pensamos, é assim que agimos. É assim que falamos sobre isto. $(\mathrm{Z} \S 309)$

Estas observações de Wittgenstein remetem-nos para um dos pontos centrais de Ser e Tempo de Heidegger, a saber, a facticidade do Dasein. A "abertura", o "aí" ( $d a)$ do Dasein (ser-aí) ou o contexto fáctico e prático em que estamos já sempre lançados não se explicam, não se fundamentam e não se justificam, mas são o horizonte inevitável de toda a explicação, fundamentação e justificação. A existência humana é assumida como um fardo (Last), perante o qual se constata simplesmente que "as coisas são e têm de 
ser assim" (SZ 134: "Daß es ist und zu sein hat"). Também o tema wittgensteiniano da "ausência de fundamento das nossas crenças" ("Grundlosigkeit unseres Glaubens"; ÜG §166), desempenha um papel crucial no contexto da obra de Heidegger. O Dasein é considerado como um fundamento abismal (abgründiger Grund) ${ }^{26}$ e também como fundamentum concussum, ${ }^{27}$ constituindo esta última expressão uma alusão crítica à busca cartesiana de um fundamento firme e inabalável (inconcussum). Uma vez que as práticas sociais são, em última instância, contingentes, a "quotidianidade média", como Heidegger lhe chama, pode ser considerada como uma dimensão desprovida de fundamento. Em Ser e Tempo, há, inclusivamente, uma referência explícita à "ausência de fundamento [Bodenlosigkeit] do ser inautêntico no impessoal" (SZ 178).

Gadamer também destaca a facticidade da existência e sublinha o primado da história sobre a consciência humana. Por um lado, isto significa que o nosso "quadro de referências herdado" (para utilizar as palavras de Wittgenstein) determina o pensamento e a experiência do mundo; por outro lado, significa a impossibilidade de tornar a nossa existência transparente pela via da reflexão. Jogando com a etimologia da palavra alemã para "consciência", Gadamer chega a afirmar que somos mais ser (Sein) do que consciência (Bewußtsein). ${ }^{28}$ Em plena sintonia com Wittgenstein, lança as seguintes interrogações retóricas: "Carece de uma fundamentação aquilo que desde sempre nos sustenta?", "Não será que, na verdade, algo como um 'acordo de base' [tragendes Einverständnis] precede todo o mal-entendido?"30 É verdade que Gadamer, ao contrário de Wittgenstein, valoriza a análise da historicidade em detrimento de uma análise das práticas quotidianas, mas as duas perspectivas (a histórica e a pragmática) são complementares, não incompatíveis.

Apesar de a suspeita de relativismo ser compreensível, é mais correcto, todavia, ver na obra de Wittgenstein, Heidegger e Gadamer não uma defesa do relativismo, mas apenas do contextualismo. A ideia de que a justificação das nossas crenças e a compreensão dos outros depende do nosso contexto não deve ser confundida com o relativismo. Com efeito, o facto de o relativismo ser, por vezes, definido como a tese segundo a qual todas as perspectivas são igualmente válidas e verdadeiras é suficiente para não interpretar a obra dos referidos autores como uma defesa do relativismo. Veja-se o caso de Wittgenstein: precisamente por reconhecer que é a partir da nossa forma de vida e da nossa "imagem do mundo" que podemos justificar crenças e

${ }^{26}$ Cf. Wegmarken, Frankfurt am Main, V. Klostermann, 1996, pp. 122 e 174.

${ }^{27}$ Cf. Zur Sache des Denkens, Tübingen, Max Niemeyer Verlag, 1969, p. 34.

${ }^{28}$ Cf. Gadamer, Neuere Philosophie I (Gesammelte Werke 3), p. 221.

${ }^{29}$ H.-G. Gadamer, Wahrheit und Methode. Ergänzungen - Register (Gesammelte Werke 2), Tübingen, J.C.B. Mohr, 1993, p. 447.

${ }^{30}$ Idem., ibid., p. 223. 
distinguir entre o verdadeiro e o falso, ele recusa uma atitude de mera resignação perante a diversidade das formas de vida. Exemplificando, se uma tribo prefere feiticeiros a cientistas, nós seguramente combateríamos tal opção, apesar de a capacidade de dar argumentos ser, nestes casos, limitada: "Eu disse que 'combateria' o outro homem - mas não lhe indicaria razões? Certamente; mas até onde é que chegam? No fim das razões vem a persuasão. (Pense no que acontece quando os missionários convertem os nativos.)" (ÜG §612) O contextualismo não é uma aceitação passiva e indiferente de todas as perspectivas, pois o nosso contexto ou enquadramento dá-nos os meios para a crítica de outras perspectivas.

Também a associação do relativismo a uma defesa da incomunicabilidade e da incomensurabilidade constitui outra razão para evitar classificar o pensamento de Wittgenstein, Heidegger e Gadamer como relativista. É verdade que Wittgenstein chega a sugerir que, quando as tradições e as práticas são drasticamente diferentes, um homem pode ser um enigma total para outro (cf. PU 568). Todavia, entre as práticas de diferentes comunidades ou culturas existem, normalmente, pontos em comum, pontos estes que podem ser expandidos em princípio, possibilitando, assim, a compreensão intercultural. A noção gadameriana de fusão de horizontes assume, neste contexto, uma enorme importância. Ela mostra que o contextualismo é compatível com uma recusa da incomensurabilidade e da incomunicabilidade. Segundo Gadamer, apesar de ser impossível libertarmo-nos do nosso contexto histórico ou horizonte de compreensão, existe sempre a possibilidade de diálogo com outros horizontes históricos e culturais, no decurso do qual é possível corrigir os nossos preconceitos e chegar a um entendimento com outrem. $\mathrm{O}$ resultado deste processo é uma nova perspectiva sobre o assunto em questão, perspectiva esta que supera a unilateralidade dos pontos de vista iniciais dos participantes no diálogo. Não há linguagens intraduzíveis e incapazes de interagir com outras. Desde que haja um território comum do̊ ponto de vista histórico, prático ou comportamental, a possibilidade do diálogo está assegurada; e é legítimo pensar que existe sempre um território comum, por mais exíguo que seja, entre as comunidades humanas. O modelo da fusão de horizontes é, assim, uma forma de navegar entre Cila (o objectivismo ou absolutismo epistemológico) e Caríbdis (o relativismo).

Habermas defendeu, em Zur Logik der Sozialwissenschaften, que Wittgenstein não chegou a entrar no domínio da hermenêutica, ${ }^{31}$ por lhe faltar um "conceito dialéctico da tradução", ${ }^{32}$ ou seja, por ter descurado o modo como, nos processos de compreensão, diferentes horizontes linguísticos interagem e se transformam. Ainda segundo Habermas, Wittgenstein teria

${ }^{31}$ Cf. Jürgen Habermas, Zur Logik der Sozialwissenschaften, Frankfurt am Main, Suhrkamp, 1985, p. 264.

${ }^{32}$ Idem, ibid., p. 276. 
defendido uma "monadologia de jogos de linguagem", 33 de acordo com a qual os jogos de linguagem estariam associados a formas de vida fechadas, consistindo a compreensão da linguagem e das práticas de uma comunidade na "reprodução de um padrão fixo". ${ }^{34}$ A interpretação de Habermas é, porém, discutível. Wittgenstein não explorou, é certo, o tema da fusão de horizontes, de formas de vida ou imagens do mundo. Mas uma lacuna não é uma divergência de fundo. Ingredientes fundamentais do modelo da fusão de horizontes estão presentes na obra de Wittgenstein: a possibilidade de aceder a outras línguas; a ideia de que toda a compreensão é condicionada por uma pré-compreensão, mais precisamente, por uma rede de actividades linguísticas e não linguísticas; e, por último, a consciência do carácter dinâmico da linguagem. A seguinte passagem, apesar de algum défice de clareza, evoca a noção de fusão de horizontes:

O nosso conhecimento de muitas línguas obsta a que tomemos muito a sério as filosofias que estão depositadas [niederlegt] nas formas de uma delas. Mas aqui estamos cegos perante o facto de que nós mesmos temos fortes preconceitos a favor e contra certas formas de expressão; que esta acumulação peculiar de várias línguas suscita para nós uma determinada imagem. (Z §323)

Integrando esta passagem no contexto do pensamento de Wittgenstein, é possível dissipar a sua obscuridade e dela extrair algumas conclusões importantes de um ponto de vista hermenêutico: (1) a referência às "filosofias" depositadas nas formas das diversas línguas remete-nos para o facto de uma língua ser portadora de uma determinada inteligibilidade ou imagem do mundo; (2) os "fortes preconceitos" a que Wittgenstein alude parecem coincidir, pelo menos parcialmente, com a concepção gadameriana dos preconceitos como uma pré-compreensão do mundo e como linhas organizadoras da experiência; (3) a língua não é uma prisão, pois é possível aceder a outros universos linguísticos; (4) aceder a outras línguas não significa fazer abstracção do nosso universo linguístico, pois este condiciona a nossa abertura a outras línguas - esta parece ser a interpretação mais natural da afirmação segundo a qual a acumulação ou sobreposição (Übereinanderlagerung) de línguas dá como resultado uma "imagem determinada. ${ }^{35} \mathrm{O}$ que faltou a Wittgenstein foi uma maior consciência dos méritos decorrentes da interacção

${ }^{33}$ Idem, ibid., p. 272.

${ }^{34}$ Idem, ibid., p. 278.

${ }^{35}$ Michael Zimmermann propõe uma interpretação semelhante da referida passagem, defendendo que Wittgenstein estaria a retomar um dos pontos centrais da filosofia da linguagem de Humboldt, a saber, que a abertura a outras línguas permanece sempre condicionada pela língua materna, apesar de ser possível ultrapassar os limites fixados por esta última (cf. M. Zimmermann, op. cit., pp. 101 e 139). 
entre línguas ou formas de vida, sobretudo do ponto de vista da crítica dos nossos preconceitos.

\section{Conclusão}

De um ponto de vista hermenêutico, a obra de Wittgenstein apresenta um duplo interesse: por um lado, contém análises iluminadoras de noções como a compreensão e o significado; por outro lado, tais análises têm afinidades significativas com a corrente hermenêutica da filosofia contemporânea. Importa salientar que o estudo de tais afinidades é mais do que uma mera curiosidade histórica, visto que uma correcta orquestração de temas e ideias presentes na obra de Wittgenstein, Heidegger e Gadamer permite articular melhor algumas das suas intuições e evitar deficiências ou limitações que se podem encontrar na obra de cada um deles. É possível justificar de forma breve esta afirmação. Em primeiro lugar, Wittgenstein caracteriza-se por uma atitude fortemente antimetafísica, declinando temas hermenêuticos não do ponto de vista de uma "história do ser", como Heidegger, mas do ponto de vista de uma "história natural" (PU §415). Deste modo, torna-se possível abrir a filosofia hermenêutica a perspectivas de inspiração naturalista e divorciadas da tradição metafísica, a qual desempenha um papel fulcral na obra de Heidegger e de Gadamer. Em segundo lugar, uma coordenação entre os três filósofos analisados permite responder de forma convincente à objecção de relativismo que lhes é amiúde dirigida. A este nível, o modelo gadameriano da fusão de horizontes é, como se viu, essencial. Em terceiro lugar, existe o problema do quietismo. O reconhecimento da forma de vida como dimensão última da existência humana dá lugar, em Wittgenstein, a uma atitude de resignação; só é possível combater outras formas de vida. Em Heidegger, e mais precisamente em Ser e Tempo, a atitude crítica perante os padrões comunitários assumiu a forma de um apelo à autenticidade; sucede, porém, que tal apelo pode ser considerado como mera expressão de um decisionismo vazio. ${ }^{36}$ Em contrapartida, a hermenêutica de Gadamer oferece um antídoto eficaz contra o quietismo, graças à concepção dialógica da compreensão e à defesa da abertura à alteridade como forma de detectar e corrigir os nossos preconceitos.

Em suma, uma correcta articulação dos contributos de Wittgenstein, Heidegger e Gadamer permite, em oposição à herança cartesiana, esclarecer de forma adequada a dimensão pragmática e social do conhecimento e da linguagem.

${ }^{36}$ Cf. Jürgen Habermas, Der philosophische Diskurs der Moderne, Frankfurt am Main, Suhrkamp, 1988, p. 183. 


\begin{abstract}
The article attempts to articulate Wittgensteinian and hermeneutic views of knowledge, language and understanding. Wittgenstein is not a member of the so-called hermeneutic tradition, but his late work has important affinities with the work of hermeneutic thinkers like Heidegger and Gadamer. Firstly, Wittgenstein and hermeneutics share a basic philosophical attitude that can be termed as "phenomenology of everydayness". An important result of such an approach is the acknowledgement of the pragmatic and social dimension of knowledge. Secondly, Wittgenstein, Heidegger and Gadamer reject formal or systematic theories of meaning and claim that language is the universal medium of human experience. Thirdly, they conceive of understanding as a practical ability. Wittgenstein helps us to clarify some hermeneutic themes and dèvelops them from an antimetaphysical standpoint. On the other hand, hermeneutics can refine some aspects of Wittgenstein's thought; a case in point is the Gadamerian doctrine of the fusion of horizons, which avoids the danger of relativism that lurks in Wittgenstein's late work. A comparative study of Wittgenstein and hermeneutics contributes therefore to effective philosophical progress.
\end{abstract}




\section{LISTA DE ABREVIATURAS}

\section{Wittgenstein}

BB: Das Blaue Buch (Werkausgabe, Bd. 5), Frankfurt am Main, Suhrkamp, 1984.

PB: Philosophische Bemerkungen (Werkausgabe, Bd. 2), Frankfurt am Main, Suhrkamp, 1984.

PG: Philosophische Grammatik (Werkausgabe, Bd. 4), Frankfurt am Main, Suhrkamp, 1984.

PU: Philosophische Untersuchungen (Werkausgabe, Bd. 1), Frankfurt am Main, Suhrkamp, 1984.

ÜG: Über Gewißheit (Werkausgabe, Bd. 8), Frankfurt am Main, Suhrkamp, 1984.

Z: Zettel (Werkausgabe, Bd. 8), Frankfurt am Main, Suhrkamp, 1984.

\section{Heidegger}

SZ: Sein und Zeit, Tübingen, Max Niemeyer Verlag, ${ }^{17} 1993$.

\section{Gadamer}

WM: Wahrheit und Methode (Gesammelte Werke 1), Tübingen, J.C.B. Mohr, ${ }^{6} 1990$. 